Klicia Nogueira Hayden

Variação e mudança semântica: A preposição por com valor final

DISSERTAÇÃO DE MESTRADO

DEPARTAMENTO DE LETRAS

Programa de Pós-Graduação em Letras 


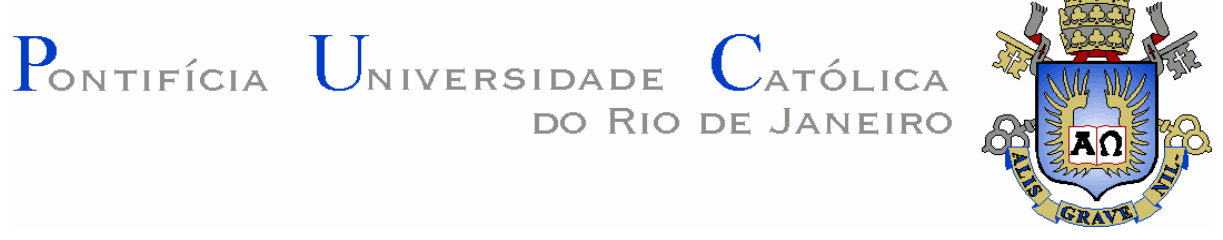

Klicia Nogueira Hayden

Variação e mudança semântica:

A preposição por com valor final

Dissertação de Mestrado

Dissertação apresentada ao Programa de Pós-Graduação em Letras do Departamento de Letras da PUC-Rio como requisito parcial para obtenção do grau de Mestre em Letras.

Orientadora: Prof ${ }^{a}$. Drª . Eneida do Rêgo Monteiro Bomfim 
Klícia Nogueira Hayden

\section{Variação e mudança semântica: a preposição por com valor final}

Dissertação apresentada como requisito parcial para obtenção do grau de Mestre pelo Programa de Pós-Graduação em Letras do Departamento de Letras do Centro de Teologia e Ciências Humanas da PUC-Rio. Aprovada pela Comissão Examinadora abaixo assinada.

Profa. Eneida do Rêgo Monteiro Bomfim

Orientadora

Departamento de Letras - PUC-Rio

Profa. Maria de Fátima Duarte Henrique dos Santos

Departamento de Letras - PUC-Rio

Profa. Cecilia Maria Aldigueri Goulart

UFF

Prof. Paulo Fernando Carneiro de Andrade

Coordenador Setorial do Centro de Teologia

e Ciências Humanas - PUC-Rio

Rio de Janeiro, 9 de julho de 2009. 
Todos os direitos reservados. É proibida a reprodução total ou parcial do trabalho sem autorização da universidade, da autora e da orientadora.

\section{Klicia Nogueira Hayden}

Graduou-se em Letras pela UERJ (Universidade do Estado do Rio de Janeiro), em 2005. Pós-graduada em Língua Portuguesa, pelo Liceu Literário Português, em 2006. Participou de diversos congressos na área de Estudos da Linguagem. É Instructional Designer e supervisora de diversos MBAs corporativos a distância, pela Fundação Getulio Vargas.

Ficha Catalográfica

Hayden, Klicia Nogueira

Variação e mudança semântica: a preposição por com valor final / Klicia Nogueira Hayden ; orientadora: Eneida do Rêgo Monteiro Bomfim. - 2009.

59 f. : il. ; $30 \mathrm{~cm}$

Dissertação (Mestrado em Letras)-Pontifícia Universidade Católica do Rio de Janeiro, Rio de Janeiro, 2009.

Inclui bibliografia

1. Letras - Teses. 2. Preposições para e por. 3. Valores de preposições. 4. Valor de finalidade. 5. Diacronia. 6. Português arcaico. 7. Português moderno. 8. Português contemporâneo. 9. Recursos estilísticos. I. Bomfim, Eneida. II. Pontifícia Universidade Católica do Rio de Janeiro. Departamento de Letras. III. Título. 
Para Deus, que me guiou em todos os caminhos, para meus pais, Francisco Carlos e Maria Auxiliadora, que tanto me incentivaram para a conclusão deste trabalho e para minha irmã Karla, que mesmo longe, torceu muito por mim. 


\section{Agradecimentos}

Á minha orientadora Professora Eneida do Rego Monteiro Bomfim pela grande ajuda na confeccção deste trabalho e pela paciência ao longo dos meses.

Aos meus pais, Francisco Carlos e Maria Auxiliadora, por todo o apoio, educação e carinho de todas as horas.

À minha querida irmã, Karla, pelo carinho e incentivo.

Aos meus amigos, Ulysses, Patricia, Livia, Gisele, Rafaella, e colegas da FGV, que tanto torceram para que eu concluísse o trabalho com êxito.

Às professoras Fátima Santos e Cecília, que, gentilmente, se dispuseram a participar da Comissão examinadora.

À Chiquinha, pela constante prestatividade e prontidão.

A todos os amigos e familiares que de uma forma ou de outra me estimularam ou me ajudaram. 


\section{Resumo}

Hayden, Klicia Nogueira; Bomfim, Eneida do Rego M. Variação e mudança semântica: a preposição por com valor final. Rio de Janeiro, 2009. 59p. Dissertação de Mestrado - Departamento de Letras, Pontifícia Universidade Católica do Rio de Janeiro.

A proposta deste trabalho foi discutir as ocorrências da preposição por com valor final em textos portugueses dos séculos XIII ao XX, observando as ocasiões que fizeram com que ela fosse gradativamente substituída por outra preposição: para. Vê-se que, em textos mais antigos, a ocorrência de por com valor final prevalecia e, nos mais recentes, predomina para.O emprego de por final tornou-se estilístico. Pretendeu-se, neste trabalho, arrolar os diferentes valores das preposições em estudo, exemplificando com autores brasileiros do século XIX, como Machado de Assis, José de Alencar e Lima Barreto, e do século XX, como Jorge Amado e José Lins do Rego. A acepção de finalidade em por não foi encontrada em autores do século XX. Ela foi levantada para ilustrar o desaparecimento contínuo deste uso ao longo dos anos. O trabalho tem cunho histórico. Segue um enfoque funcionalista e, na pesquisa dos dados, apoia-se na sociolinguística variacional, nos moldes de Labov, tal como foi divulgada entre nós por Tarallo (1986 e 1990).

\section{Palavras - chave}

Preposições para e por; valores de preposições; valor de finalidade; diacronia; português arcaico; português moderno; português contemporâneo; recursos estilísticos. 


\section{Abstract}

Hayden, Klicia Nogueira; Bomfim, Eneida do Rego M (Advisor). Semantics variation and change: preposition por meaning purpose. Rio de Janeiro, 2009. 59p. MSc. Dissertation - Departamento de Letras, Pontifícia Universidade Católica do Rio de Janeiro.

The aim of this work is to discuss the occurrence of the preposition por meaning purpose in texts in Portuguese language from XIII to XX centuries, observing the ocasions that this preposition have been gradually replaced by another one: the preposition para. It's noticeable that, in older texts, occurrences of preposition por meaning purpose are majority, whereas, in most recent texts, preposition para occurs more frequently. The use of preposition por meaning purpose became only a matter of style. We intended to understand the different meanings of the prepositions we're analyzing, through illustrations from Brazilian authors from the XIX century, Machado de Assis, José de Alencar and Lima Barreto; and from the XX century, Jorge Amado and José Lins do Rego. The particular meaning of purpose in preposition por has not been found in any author from the XX century. We intended to demonstrate the process of continuous disappearance of proposition por meaning purpose throughout the $\mathrm{XX}$ century. This work follows a historical approach. It adopts a functionalist perspective, and the collecting of data is based on Labov's variationist sociolinguistics, as introduced in Brazil by Tarallo (1986 e 1990).

\section{Keywords}

Prepositions para and por; preposition meanings; purpose meaning; diacronism; archaic Portuguese; modern Portuguese; contemporary Portuguese; style. 


\section{SUMÁRIO}

1.Introdução

12

2.Revisão da literatura e Fundamentação Teórica 18

2.1.As preposições por e para nas gramáticas do modelo tradicional 18

$\begin{array}{ll}2.2 . \text { Estudos específicos } & 28\end{array}$

3.Metodologia de trabalho 33

3.1.Breve notícia sobre o enfoque funcionalista 34

3.2.Periodização da língua portuguesa 38

4.A concorrência entre para e por com valor final 39

4.1.Do século XIII até a fase moderna do português 39

4.2.Do português moderno ao contemporâneo 45

5.Considerações finais 53

6.Referências Bibliográficas $\quad 55$ 


\section{Lista de Siglas}

\section{Siglas dos autores}

AV - Pe. Antonio Vieira

BG - Bartolomeu Guerreiro

JA - José de Alencar

JAm - Jorge Amado

JLR - José Lins do Rego

LAV - Luís Antônio Verney

LB - Lima Barreto

MA - Machado de Assis

TAG - Tomás Antônio Gonzaga

\section{Siglas dos textos}

Dec. - Década I da Ásia de João de Barros

DSG - Demanda do Santo Graal

CGE - Crônica Geral de Espanha

ESO - Esmeraldo de situ orbis

GFO - Gramática de Fernão de Oliveira

LE - Livro da Ensinança do Bem Cavalgar Toda Sela

LL - Livro de Linhagens

Lus. - Lusíadas 
(...) a preposição mostra que entre o antecedente $e$ o consequente há uma relação, de tal modo que o sentido do primeiro é explicado ou completado pelo segundo.

Mário Pereira de Sousa Lima 